\title{
HUBUNGAN RIWAYAT PERLAKUAN KEKERASAN DENGAN KEJADIAN MENARIK DIRI PENDERITA SKIZOFRENIA DI RUANG MURAI BDAN ANGGREK RSKJ PROVINSI BENGKULU
}

\section{Relationship of Violence BehaviorHistory with Incidence of Social Isolation in Murai Band Anggrek Ward RSKJ Soeprapto Bengkulu}

\author{
${ }^{1}$ Ade Herman Surya Direja, ${ }^{2}$ Loren Juksen, ${ }^{3}$ Pera Daniarti \\ Program Studi Ilmu Keperawatan STIKES Tri Mandiri Sakti Bengkulu \\ Email:1juksenloren@yahoo.com, 2adehermansuryadireja@gmail.com³peradaniartitms@gmail.com
}

\begin{abstract}
ABSTRAK
Menarik diri adalah keadaan dimana seorang individu mengalami penurunan atau bahkan sama sekali tidak mampu berinteraksi dengan orang lain di sekitarnya yang di tampilkan berupa reaksi fisik maupun psikologis. Penelitian ini bertujuan untuk mempelajari hubungan Riwayat Perlakuan Kekerasan dengan Kejadian Menarik Diri Penderita Skizofrenia di Ruang Murai B Dan Anggrek RSKJ Provinsi Bengkulu.Penelitian ini menggunakan desain penelitian deskriptif.Populasi dari penelitian ini adalah seluruh penderita skizofrenia yang di rawat di Ruang Murai B dan Ruang Anggrek Rumah Sakit Khusus Jiwa Soeprapto Bengkulu yang berjumlah 72 pasien. Teknik pengambilan sampel dalam penelitian ini menggunakan teknik Total Sampling yaitu seluruh populasi dijadikan sampel, artinya seluruh penderita skizofrenia yang dirawat di Ruang Murai B dan Ruang Anggrek Rumah Sakit Khusus Jiwa Soeprapto Provinsi Bengkulu yang berjumlah 72 pasien. Pengumpulan data dalam penelitian ini menggunakan data sekunder yang diperoleh dari rekam medik dan data primer yang diperoleh dari pengkajian langsung dengan mengisi format check list. Analisis data dalam penelitian ini adalah analisis univariat dan bivariate dengan uji Chi Square $\left(\chi^{2}\right)$ dan Contingency Coefficient (C). Hasil penelitian didapatkan: (1) dari 72 orang pasien terdapat 41 orang $(56,9 \%)$ menarik diri dan 31 orang $(43,1 \%)$ tidak menarik diri; (2) dari 72 pasien terdapat 47 orang $(65,3 \%)$ yang memiliki riwayat perlakuan kekerasan dan 25 orang $(34,7 \%)$ tidak memiliki riwayat perlakuan kekerasan; (3) dari 47 orang pasien yang mempunyai riwayat perlakuan kekerasan terdapat 32 orang $(68,1 \%)$ menarik diri dan 15 orang $(31,9 \%)$ tidak menarik diri; (4) dari 25 orang yang tidak ada riwayat perlakuan kekerasan terdapat 9 orang (36\%) menarik diri dan 16 orang (64\%) tidak menarik diri; (5) Hasil uji statistik chi-square (continuity correction) didapat nilai $\chi^{2}=5,606$ dengan asymp.sig. $(\mathrm{p})=0,018<0,05$ berarti signifikan, maka Ho ditolak dan Ha diterima. Ada hubungan riwayat perlakuan kekerasan dengan kejadian menarik diri penderita skizofrenia di RSKJ Soeprapto Provinsi Bengkulu Tahun 2018 dengan kategori hubungan sedang. Diharapkan tenaga kesehatan dapat menerapkan konsep komunikasi terapeutik kepada semua pasien dan memberikan jadwal kegiatan yang teratur sehingga tidak ada pasien skizofrenia yang menarik diri dari lingkungan dan orang lain.
\end{abstract}

Kata Kunci: menarik diri, perlakuan kekerasan, skizofrenia

\section{ABSTRACT}

Social Isolation is a condition in which an individual experiences a decrease or is not even able to interact with others around him in the form of physical or psychological reactions. The purpose of this study is to determine the Relationship of Violence Behavior history with Incidence of Social Isolation in Murai B and Anggrek Ward RSKJ Soeprapto Bengkulu. This study used descriptive approach with cross sectional design. Population in this study were all patients diagnosed with schizophrenia who treated in Murai B and Anggrek Ward RSKJ Soeprapto Bengkulu with the amount of 72 patients. Sampling technique in this study used total sampling that were all population being 
sample. Collecting data in this study used primary data with assessment directly with filled out checklist format and secondary data used medical record. Data analysis used Chi-Square (X2) and contingency coefficient test $(C)$. The result of this study showed: (1) from 72 patients there were 41 people (56,9\%) 47 Social Isolation and 31 people $(43,1 \%)$ did not Social Isolation; (2) from 72 patients there were 47 people (65,3\%) with Violence Behavior history and 25 people $(34,7 \%)$ did not have Violence Behavior history; (3) from 47 people with Violence Behavior history there were 32 people $(68,1 \%)$ Social Isolation and 15 people $(31,9 \%)$ did not Social Isolation. (4) From 25 people did not Violence Behavior history there were 9 people (36\%) Social Isolation and 16 people (64\%) did not Social Isolation. (5) results of statistic test chi-square (continuity correction) obtained $x=$ 5,606 with asymp.sig. $(p)=0,0180,05$ means significant, so that Ho rejected and Ha accepted. There is significant relationship between Violence Behavior history with Incidence of Social Isolation in Murai $B$ and Anggrek Ward RSKJ Soeprapto Bengkulu in 2018 with moderate category relationship. It is expected that health workers can apply the concept of therapeutic communication to all patients and provide a regular schedule of activities so that no schizophrenic patients Social Isolation from the environment and others

Keywords: violence behavior history, incidence of Social Isolation, schizophrenia

\section{PENDAHULUAN}

Gangguan jiwa menurut American Psychiatric Association (APA) adalah sindrom atau pola psikologis atau pola perilaku yang penting secara klinis, yang terjadi pada individu dan sindrom itu dihubungkan dengan adanya distress (misalnya, gejala nyeri, menyakitkan) atau disabilitas (ketidakmampuan pada salah satu bagian atau beberapa fungsi penting) atau disertai peningkatan resiko secara bermakna untuk mati, sakit, ketidakmampuan, atau kehilangan kebebasan (APA, 1994 dalam Prabowo, 2014).

Gangguan jiwa yang menjadi salah satu masalah utama di negara-negara berkembang adalah Skizofrenia.Skizofrenia termasuk jenis psikosis yang menempati urutan atas dari seluruh gangguan jiwa yang ada (Nuraenah, 2015).Skizofrenia adalah Suatu penyakit yang mempengaruhi otak dan menyebabkan timbulnya pikiran, persepsi, emosi, gerakan dan perilaku yang aneh dan terganggu. Gejala skizofrenia dibagi dalam 2 kategori utama: gejala positif atau gejala nyata, yang mencakup waham, halusinasi dan disorganisasi pikiran, bicara dan perilaku yang tidak teratur serta gejala negative atau gejala samar, seperti afek datar, tidak memiliki kemauan dan menarik diri dari masyarakat atau rasa tidak 3 nyaman (Videbeck, 2008).
Apabila penduduk Indonesia sekitar 200 juta jiwa, maka diperkirakan sekitar 2 juta jiwa menderita skizofrenia, dimana sekitar 99\% pasien di RS Jiwa di Indonesia adalah penderita skizofrenia (Arif, 2006). Penderita skizofrenia sering mendapat stigma dan diskriminasi yang lebih besar dari masyarakat di sekitarnya dibandingkan individu yang menderita penyakit medis lainnya.Mereka sering mendapat perlakuan yang tidak manusiawi, misalnya perlakuan kekerasan, diasingkan, diisolasi atau dipasung.Mereka sering sekali disebut sebagai orang gila (insanity atau madness).Ini mungkin disebabkan karena ketidaktahuan atau pengertian yang salah dari keluarga atau anggota masyarakat mengenai skizofrenia.Masyarakat pada umumnya mengesampingkan bahwa perubahan pada seseorang yang menderita skizofrenia berhubungan dengan kepribadiannya yang terpecah, tetapi masyarakat lebih menekankan kepada penderita bahwa mereka adalah orang yang sangat berbahaya bagi lingkungan sekitarnya.

Kemunduran fungsi sosial yang di alami seseorang di dalam diagnosa keperawatan jiwa di sebut menarik diri. Menarik diri adalah keadaan dimana seorang individu mengalami penurunan atau bahkan sama sekali tidak mampu berinteraksi dengan orang lain di sekitarnya (Purba, 2008). 
Menarik diri adalah reaksi yang di tampilkan dapat berupa reaksi fisik maupun psikologis.Reaksi fisik yaitu individu pergi atau menghindari stressor.misalnya menjauhi polusi, sumber infeksi, gas beracun dll.Sedangkan reaksi psikologis individu menunjukkan prilaku apatis, mengisolasi diri, tidak berminat sering disertai rasa takut dan bermusuhan.

Perlakuan kekerasan adalah tingkah laku individu yang di tujukan untuk melukai atau mencelakakan individu lain yang tidak menginginkan datang nya tingkah laku tersebut (Purba dkk, 2008). Prilaku kekerasan adalah nyata melakukan kekerasan di tujukan pada diri sendiri/ orang lain secara verbal maupun non verbal dan pada lingkungan (Depkes RI, 2009).

Data yang diperoleh di rumah sakit khusus jiwa Soeprapto Bengkulu, penderita skizofrenia pada tahun 2014 sebanyak 5.703 orang dengan pasien yang rawat inap di rumah sakit jiwa sebanyak 3.851 orang dan sisanya rawat jalan, pada tahun 2015 terjadi peningkatan jumlah pasien skizofrenia yakni menjadi 6.870 dan pasien yang rawat inap di rumah sakit jiwa sebanyak 1.958 orang dan sisanya rawat jalan, pada tahun 2016 terjadi peningkatan jumlah pasien skizofrenia yakni menjadi 7.865 dan pasien yang rawat inap di rumah sakit jiwa sebanyak 1.400 orang dan sisanya rawat jalan, dan pada tahun 2017 terjadi peningkatan jumlah pasien skizofrenia yakni menjadi 8.352 dan pasien yang rawat inap di rumah sakit jiwa sebanyak 1.640 orang dan sisanya rawat jalan. (RSKJ Soeprapto Provinsi Bengkulu, 2017).

Rumusan masalah dalam penelitian ini adalah apakah terdapat hubungan riwayat perlakuan kekerasan dengan kejadian menarik diri penderita skizofrenia di ruang Murai B dan Anggrek RSKJ Provinsi Bengkulu?.Tujuan penelitian ini bertujuan untuk mempelajari hubungan riwayat perlakuan kekerasan dengan kejadian menarik diri penderita skizofrenia di ruang Murai B dan Anggrek RSKJ Provinsi Bengkulu.

\section{METODE PENELITIAN}

Penelitian ini menggunakan desain penelitian deskriptif.Populasi dalam penelitian ini adalah seluruh pasienskizofrenia yang dirawat inap di Murai B dan Anggrek RSKJ Soeprapto Provinsi Bengkulu periode tahun 2018 yang berjumlah 72 orang. Sampel dalam penelitian ini menggunakan total sampling sebanyak 72 orang.Metode dalam pengumpulan data pada penelitian ini adalah dengan menggunakan data sekunder dan data primer.Data sekunder didapat dengan studi dokumentasi catatan rekam medik dan laporan tahunan yang ada di RSKJ Soeprapto Provinsi Bengkulu.Data primer didapat dengan pengkajian langsung kepada pasien.Data dianalisis menggunakan analisis univariat dan bivariate menggunakan uji Chi-square dan uji statistik Contingency Coefficient (C).

\section{HASIL PENELITIAN}

1. Analisis Univariat

Analisis ini dilakukan untuk mendapatkan gambaran tentang distribusi frekuensi variabel independen (riwayat perlakuan kekerasan) dengan variabel dependen (menarik diri) pada pasien skizofrenia yang di rawat inap di Ruang Murai B dan Anggrek RSKJ Soeprapto Provinsi Bengkulu.

Tabel 1.Distribusi Frekuensi Menarik Diri pada Pasien Skizofrenia di Ruang Murai Bdan Anggrek RSKJ Soeprapto Provinsi Bengkulu.

\begin{tabular}{ccc}
\hline Menarik Diri & Frekuensi & Persentase (\%) \\
\hline Ya & 41 & 56.9 \\
Tidak & 31 & 43.1 \\
\hline Total & 72 & 100.0 \\
\hline
\end{tabular}


Dari tabel 1 di atas dapat diketahui bahwa dari 72 orang pasien terdapat 41 orang $(56,9 \%)$ menarik diri dan 31 orang $(43,1 \%)$ tidak menarik diri.

Tabel 2.Distribusi Frekuensi Riwayat Perlakuan Kekerasan pada Pasien Skizofrenia di Ruang Anggrek dan Murai C RSKJ Soeprapto Provinsi Bengkulu

\begin{tabular}{ccc}
\hline Riwayat Perlakuan Kekerasan & Frekuensi & Persentase (\%) \\
\hline Ya & 47 & 65.3 \\
Tidak & 25 & 34.7 \\
\hline Total & 72 & 100.0 \\
\hline
\end{tabular}

Dari tabel 2 di atas dapat diketahui bahwa dari 72 pasien terdapat 47 orang $(65,3 \%)$ yang memiliki riwayat perlakuan kekerasan dan 25 orang $(34,7 \%)$ tidak memiliki riwayat perlakuan kekerasan.
2. Analisis Bivariat

Analisis ini di gunakan untuk mengetahui hubungan antara variabel independen (riwayat perlakuan kekerasan) dengan variabel dependen (menarik diri) pada pasien skizofrenia yang dirawat di Ruang Murai B dan Anggrek RSKJ Soeprapto Provinsi Bengkulu.

Tabel 3.Hubungan Riwayat Perlakuan Kekerasan dengan Kejadian Menarik diri pada Pasien Skizofrenia yang dirawat di Ruang Murai B dan AnggrekRSKJ Soeprapto Provinsi Bengkulu

\begin{tabular}{ccccccc}
\hline \multirow{2}{*}{$\begin{array}{c}\text { Riwayat Perlakukan } \\
\text { Kekerasan }\end{array}$} & \multicolumn{3}{c}{ Perilaku Menarik Diri } & \multirow{2}{*}{$\chi^{2}$} & $\rho$ & \multirow{2}{*}{ C } \\
\cline { 2 - 4 } Ya & Ya & Tidak & Total & & & \\
\hline Tidak & 32 & 15 & 47 & & & \\
& 9 & 16 & 25 & 5,606 & 0,015 & 0 \\
\hline Total & 41 & 31 & 72 & & & \\
\hline
\end{tabular}

Dari tabulasi silang riwayat perlakuan kekerasan dan kejadian menarik diri di atas dapat diketahui bahwa dari 47 orang yang memiliki riwayat perlakuan kekerasan terdapat 32 orang menarik diri dan 15 orang tidak menarik diri. Dari 25 orang yang tidak ada riwayat perlakuan kekerasan terdapat 9 orang menarik diri dan 16 orang tidak menarik diri.

Hasil uji statistik chi-square (continuity correction) didapat nilai $\chi^{2}=5,606$

\section{PEMBAHASAN}

Berdasarkan hasil penelitian pada tabel 2 tampak bahwa dari 72 pasien skizofrenia, terdapat 41 orang $(56,9 \%)$ menarik diri, di tandai dengan klien diam dan tidak mau banyak bicara, klien tidak mau mengikuti kegiatan, klien menyendiri dan tidak mau berinteraksi dengan orang terdekat, klien dengan asymp.sig. $(\mathrm{p})=0,018<0,05$ berarti signifikan, maka Ho ditolak dan Ha diterima. Jadi ada hubungan riwayat perlakuan kekerasan dengan kejadian menarik diri penderita skizofrenia di RSKJ Soeprapto Provinsi Bengkulu Tahun 2018.

\section{Hasil uji Contingency Coefficient} didapat nilai $\mathrm{C}=0,295$ dengan approx.sig $(\mathrm{p})=0,009<0,05$ berarti signifikan, maka kategori hubungan sedang.

memutuskan percakapan atau pergi jika diajak bercakap cakap, klien tampak sedih, ekspresi datar dan dangkal, serta kontak mata kurang. dan 31 orang $(43,1 \%)$ pasien skizofrenia yang tidak mengalami menarik diri karena masih aktif saat diajak 
berkomunikasi dan mengikuti kegiatan di dalam ruangan.

Hal ini sesuai teori Damayanti \& Iskandar (2012) bahwa menarik diri merupakan kesepian yang di alami oleh individu dan di rasakan saat di dorong oleh keberadaan orang lain dan sebagai pernyataan negatif atau mengancam. Menarik diri adalah keadaan di mana seorang individu mengalami penurunan atau bahkan sama sekali tidak mampu berinteraksi dengan orang lain di sekitarnya.

Menurut Yosep \& Sutini (2007) bahwa menarik diri adalah keadaan dimana seorang individu mengalami penurunan atau bahkan sama sekali tidak mampu berinteraksi dengan orang lain di sekitarnya. Klien mungkin merasa ditolak, tidak di terima, kesepian, dan tidak mampu membina hubungan yang berarti dengan orang lain.

Berdasarkan hasil penelitian tampak bahwa dari 72 pasien skizofrenia terdapat 47 orang $(65,3 \%)$ yang ada riwayat perlakuan kekerasan dan 25 orang $(34,7 \%)$ tidak ada riwayat perlakuan kekerasan. Riwayat perlakuan kekerasan diperoleh dari data rekam medik di Ruang Murai B dan Anggrek Rumah Sakit Khusus Jiwa Soeprapto Provinsi Bengkulu.

Perlakuan kekerasan bisa berupa kekerasan fisik maupun non fisik.Perlakuan kekerasan fisik meliputi penganiayaan, pemerkosaan, pelecehan seksual dan lainlain, sedangkan perlakuan kekerasan non fisik adalah caci maki, sindiran, penelantaran anak ataupun orang tua. Dengan adanya perlakuan kekerasan baik fisik maupun nonfisik tersebut menyebabkan seseorang menjadi tertutup bahkan tidak mau lagi berinteraksi dengan orang lain, dengan kata lain lebih suka menyendiri.

Dari tabel 4 di atas tampak tabulasi silang riwayat perlakuan kekerasan dan menarik diri, dari 47 orang yang ada riwayat perlakuan kekerasan terdapat 32 orang menarik diri dan 15 orang tidak menarik diri, dari 25 orang yang tidak ada riwayat perlakuan kekerasan terdapat 9 orang menarik diri dan 16 orang tidak menarik diri.
Pada tabel 4 tampak dari hasil tabulasi silang bahwa dari 47 pasien yang mengalami riwayat perlakuan kekerasan terdapat 15 pasien yang tidak menarik diri.Hal ini karena pada saat penelitian pasien tidak lagi mengalami menarik diri tetapi sudah berada pada tahap halusinasi, waham, atau defisit perawatan diri.

Hal ini sesuai dengan teori Trimelia (2011) bahwa pasien yang mengalami menarik diri kemudian akan mengalami halusinasi, waham dan defisit perawatan diri. Jadi, pada saat penelitian pasien berada pada tahap halusinasi atau defisit perawatan diri.

Pada tabel 4 tampak dari tabulasi silang bahwa dari 41 pasien menarik diri terdapat 9 pasien yang tidak mempunyai riwayat perlakuan kekerasan. Hal ini karena ada faktor lain yang mempengaruhi terjadinya menarik diri yaitu kesepian yang disebabkan karena ditinggalkan oleh orangorang yang dicintai, misalnya karena perceraian, ditinggal pasangan hidup/ keluarga meninggal dunia, serta faktor harga diri rendah karena merasa gagal mencapai keinginan dan adanya kekurangan fisik, misalnya gigi ompong.

Hasil penelitian ini didukung oleh teori Trimelia (2011), bahwa respon maladaptif pasien sebelum mengalami menarik diri, pasien mengalami kesepian. Pasien kesepian akan sulit merasa intim, merasa takut dan cemas. Sehingga pasien akan menarik diri. Menurut Yosep (2011) bahwa pada tahap 1 halusinasi pasien akan menghindar dari orang lain, lingkungan, takut di ketahui orang lain sehingga pasien menarik diri dari lingkungan.

Hasil penelitian ini sesuai dengan pendapat yang di kemukakan oleh Risky (2009), yang menyatakan bahwa salah satu penyebab menarik diri adalah perlakuan kekerasan.Dimana seseorang malu dengan keadaannya saat ini karena selama ini penderita tidak mendapat perlakuan yang baik dari orang-orang di sekitarnya.Penderita selalu saja mendapat cercaan yang menyinggung perasaannya, kurang perhatian dari keluarga, bahkan kadang-kadang mendapatkan tindak kekerasan.Penderita 
juga kadang mengalami pelecehan karena kekurangannya, baik dilecehkan melalui kata - kata ataupun perbuatan (Risky, 2009).

Klien merasa dirinya tidak berharga lagi sehingga merasa tidak aman dalam berhubungan dengan orang lain. Biasanya klien berasal dari lingkungan yang penuh permasalahan, ketegangan, kecemasan dimana tidak mungkin mengembangkan kehangatan emosional dalam hubungan yang positif dengan orang lain yang menimbulkan rasa aman. Dunia merupakan alam yang tidak menyenangkan, sebagai usaha untuk melindungi diri, klien menjadi pasif dan kepribadiannya semakin kaku (rigid) (Panji, 2008).

Menurut pendapat peneliti, perilaku menarik diri salah satunya disebabkan oleh perlakuan kekerasan. Yang mana seseorang mengalami keterpurukan dan merasa tidak berharga di hadapan orang lain. Perlakuan kekerasan tersebut bisa berupa kekerasan fisik maupun non fisik.Perlakuan kekerasan fisik meliputi penganiayaan, pemerkosaan, pelecehan seksual dan lain-lain, sedangkan perlakuan kekerasan non fisik adalah caci maki, sindiran, penelantaran anak ataupun orang tua. Dengan adanya perlakuan kekerasan baik fisik maupun nonfisik tersebut menyebabkan seseorang menjadi tertutup bahkan tidak mau lagi berinteraksi dengan orang lain, dengan kata lain lebih suka menyendiri.

Hal ini sejalan dengan pendapat Jeffrey C. Alexander dkk (2004: 3) yang menyatakan bahwa perlakuan kekerasan dapat menyebabkan trauma, pengertian trauma di masa awal dan secara medis yang berbeda dengan perspektif trauma secara psikologis yang diartikan sebuah peristiwa atau pengalaman yang menghancurkan rasa aman, rasa mampu dan harga diri, sehingga menimbulkan luka psikologis yang sulit disembuhkan sepenuhnya. Hal ini sebagaimana diungkapkan oleh Agus Sutiyono (2010: 104) yang menyatakan bahwa: trauma adalah jiwa atau tingkah laku yang tidak normal akibat tekanan jiwa atau cedera jasmani karena mengalami kejadian yang sangat membekas yang tidak bisa dilupakan. Trauma dapat terjadi pada anak yang pernah menyaksikan, mengalami dan merasakan langsung kejadian mengerikan atau mengancam jiwa, seperti tabrakan, bencana alam, kebakaran, kematian seseorang, kekerasan fisik, non fisik maupun seksual dan pertengkaran hebat orangtua.Berdasarkan hal tersebut, akibat dari trauma ini membentuk luka batin yang tersimpan dan berpotensi mengerogoti seseorang dalam melakukan hal-hal positif. Efeknya adalah kehidupan sesorang bisa menjadi tidak tercatat dengan baik dan bahkan menjadi pribadi yang pasif dan selalu berburuk sangka dengan orang lain. Trauma yang ditandai dengan keadaan jiwa atau tingkah laku yang tidak normal, pada sebagian kasus yang dihadapi oleh para psikolog anak.Muncul sebagai dampak dari tindak kekerasan yang dialami secara fisik ataupun secara psikis.Namun ada juga trauma yang muncul dari efek gabungan kekerasan fisik berupa cedera yang dialami secara jasmani berupa benturan.

Kekerasan adalah suatu perbuatan terhadap seseorang baik anak-anak maupun orang dewasa yang mengakibatkan kesengsaraan atau penderitaan secara fisik, psikologis, seksual, finansial, spiritual.Perlakuan kekerasan adalah setiap tindakan yang di lakukan pada seseorang yang berakibat timbulnya kesengsaraan atau penderitaan baik secara fisik, seksual, dan psikologis (Undang - Undang RI No. 23, 2004). Bentuk - bentuk atau dimensi kekerasan adalah dimensi mencakup: (1) Fisik, yaitu memukul, menampar, mencekik, menendang, melempar barang ke tubuh korban, menginjak, melukai dengan tangan kosong, atau menggunakan senjata, membunuh; (2) Psikologis, yaitu berteriak, menyumpah, mengancam, merendahkan, mengatur, melecehkan, menguntit dan memata-matai, tindakan-tindakan lain yang menimbulkan rasa takut (termasuk yang di arahkan kepada orang-orang dekat korban, misalnya keluarga, anak, suami, teman dekat, dll) (Luhumila Achie Sudarti, 2000).

Menarik diri adalah keadaan dimana seseorang individu mengalami penurunan 
atau bahkan sama sekali tidak mampu berinteraksi dengan orang lain di sekitarnya. Klien mungkin merasa di tolak, tidak di terima, kesepian, dan tidak mampu membina hubungan yang berarti dengan orang lain. (Iyus Yosep, 2011).

Dari hasil penelitian didapatkan hasil bahwa dari 72 pasien skizofrenia terdapat 47 pasien yang mengalami riwayat perlakuan kekerasan.dan dari 47 orang pasien yang mengalami perlakuan kekerasan terdapat 32 pasien yang menarik diri dan 15 orang tidak menarik diri. Hal ini karena ada faktor lain yang mempengaruhi terjadinya menarik diri yaitu kesepian dan halusinasi pada tahap 1 dan 2.

Penyebab menarik diri juga di pengaruhi oleh faktor predisposisi (pendukung) dan faktor presipitasi.Faktor predisposisi ini terdiri dari faktor perkembangan, faktor biologis dan faktor sosial budaya, sedangkan faktor presipitasi terdiri dari stressor sosial budaya, stresor psikologis, kehilangan keterikatan, (termasuk kehilangan cinta seseorang, fungsi fisik, kedudukan dan lain lain), peristiwa besar dalam hidup. (Sheila L, Videbeck, 2008)

Pada tabel 4 tampak dari hasil tabulasi silang bahwa dari 47 pasien yang mengalami riwayat perlakuan kekerasan terdapat 15 pasien yang tidak menarik diri.Hal ini karena pada saat penelitian pasien tidak lagi mengalami menarik diri tetapi sudah berada pada tahap halusinasi, waham, atau defisit perawatan diri.Selain itu, pada saat dilakukan penelitian pasien sudah pada tahap pemulihan karena perawat menerapkan intervensi keperawatan seperti SP menarik diri, mengkolaborasikan obat-obatan dalam pemantauan makan dan minum obat serta menerapkan konsep komunikasi terapeutik pada pasien menarik diri.

Dari 41 pasien menarik diri terdapat 9 pasien yang tidak mempunyai riwayat perlakuan kekerasan. Hal ini karena ada faktor lain yang mempengaruhi terjadinya menarik diri yaitu kesepian yang disebabkan karena ditinggalkan oleh orang-orang yang dicintai, misalnya karena perceraian, ditinggal pasangan hidup/ keluarga meninggal dunia, serta faktor harga diri rendah karena merasa gagal mencapai keinginan dan adanya kekurangan fisik, misalnya gigi ompong.

Solusi dari penelitian ini adalah perawat menerapkan intervensi keperawatan seperti SP menarik diri, mengkolaborasikan obat-obatan dalam pemantauan dalam makan dan minum obat. Perawat harus menerapkan konsep komunikasi terapeutik kepada semua pasien dan memberikan jadwal kegiatan yang teratur sehingga tidak ada pasien skizofrenia yang menarik diri dari lingkungan dan orang lain.

\section{KESIMPULAN}

1. Dari 72 pasien skizofrenia terdapat 41 orang $(56,9 \%)$ menarik diri di Ruang Murai B dan Anggrek Rumah Sakit Khusus Jiwa Soeprapto Provinsi Bengkulu.

2. Dari 72 pasien skizofrenia terdapat 47 orang $(65,3 \%)$ yang ada riwayat perlakuan kekerasan di Ruang Murai B dan Anggrek Rumah Sakit Khusus Jiwa Soeprapto Provinsi Bengkulu

3. Dari 47 orang pasien yang ada riwayat perlakuan kekerasan ada 32 pasien yang menarik diri dan 15 orang tidak menarik diri di Ruang Murai B dan Anggrek Rumah Sakit Khusus Jiwa Soeprapto Provinsi Bengkulu.

4. Ada hubungan antara riwayat perlakuan kekerasan dengan kejadian menarik diri pada pasien skizofrenia di Ruang Murai B dan Anggrek Rumah Sakit Khusus Jiwa Soeprapto Provinsi Bengkulu dengan kategori hubungan sedang.

\section{DAFTAR PUSTAKA}

Achie Sudarti Luhulima. 2000. Pemahaman Bentuk-bentuk Kekerasan

Terhadap.Perempuan dan Alternatif Pemecahan. Jakarta: UI Press

Alexander, Jeffery C. dkk. 2004. Cultural Trauma and Collective Identity. London, England: University of California Press, Ltd.

Arif, I. S. (2006).Skizofrenia: Memahami Dinamika Keluarga Pasien. Bandung: Rafika Aditama 
Damayanti, M., \& Iskandar. 2012. Asuhan Keperawatan Jiwa. Bandung: Refika Aditama.

Direja, Ade. H. S. 2011. Buku Ajar Asuhan Keperawatan Jiwa. Yogyakarta: Nuha Medika

Nuraenah.2015. Tesis Hubungan Dukungan Keluarga Dan Beban Keluarga Dalam Merawat Anggota Dengan Riwayat Perilaku Kekerasan Di RS.Jiwa Islam Klender Jakarta Timur.Program Magister Ilmu KeperawatanKekhususan Keperawatan Jiwa Fakultas Ilmu Keperawatan UniversitasIndonesia Depok. Prabowo, E. 2014.Konsep \& Aplikasi Asuhan Keperawatan Jiwa. Yogyakarta: Nuha Medika
Purba, dkk.2008.Asuhan Keperawatan pada Klien dengan Masalah psikologi danGangguan Jiwa. Medan: USU Press.

RSKJ Soeprapto. 2017. Data Rekam Medik. Bengkulu: RSKJ Soeprapto

Sutiyono, Agus. 2010. Dahsyatnya Hypnoparenting. Jakarta: Penebar Plus.

Trimelia. 2011. Asuhan Keperawatan Klien Halusinasi. Jakarta: CV.Trans Info Media.

Videbeck, Sheila L. 2008. Buku Ajar Keperawatan Jiwa. Jakarta: EGC

Yosep, I. 2011. Keperawatan Jiwa. Bandung: PT Refika Aditama

Yosep.I dan Titin Sutini.2014.Buku Ajar Keperawatan Jiwa. Bandung: PT Reflika Aditama. 